\title{
Rapid Enzymatic Burn Debridement: Review of Seven Clinical Studies
}

Yaron Shoham ${ }^{1,2}$, Lior Rosenberg ${ }^{1,2}$, Yuval Krieger ${ }^{1}$, Guy Rubin ${ }^{3}$, Frank Sander ${ }^{4}$, Jan Koller ${ }^{5}$, Keren David², Dana Egozí, Rajeev B Ahuja ${ }^{7}$, Adam J Singer ${ }^{8}$ 'Soroka University Medical Center, Beer Sheva, Israel, ${ }^{2}$ MediWound Ltd, ${ }^{3}$ Haemek Medical Center, Afula, Israel, ${ }^{4}$ Unfallkrankenhaus Berlin, Germany, ${ }^{5}$ University

Hospital, Bratislava, Slovakia, ${ }^{6}$ Kaplan Medical Center, Rehovot, Israel, ${ }^{7}$ Lok Nayak Hospital, New Delhi, India, ${ }^{8}$ Stony Brook University, New York, USA

Objectives: The ideal burn debridement agent should be effective, fast, selective and non traumatic with minimal blood loss and maximal preservation of non-injured dermis. Surgical debridement is effective but traumatic and non-selective, and current non-surgical methods are inefficiently slow. NexoBrid ${ }^{\circledR}$ (NXB), a Bromelain based enzymatic debridement agent extracted from pineapple stems (Figure 1), was developed to overcome these disadvantages, and its use is growing steadily in the EU and other areas. The objective of this work is to provide a comprehensive review of all clinical studies done with NXB.

Methods: Seven different clinical studies assessing the short and long term effects of NXB on deep thermal burns covering up to $67 \%$ TBSA were compiled. Of those, four were controlled (compared to the Standard of Care - SOC) and 2 were observer-blinded. All studies were approved by the participating Institutional Review Boards and were conducted in accordance with national and international guidelines. A summary of the study designs and endpoints is presented in Tables I and II.

\begin{tabular}{||l|l|}
\hline \multicolumn{2}{|l|}{ Table II - Endpoints } \\
\begin{tabular}{||l|l|}
\hline Endpoint & Study \\
\hline Efficacy of eschar removal & All studies \\
\hline Time to complete debridement & All studies \\
\hline$\%$ wound excised, \% wounds autografted & $\begin{array}{l}\text { Studies \#2, \#6 } \\
\text { (phases 2\&3) }\end{array}$ \\
\hline Time to wound closure & All studies \\
\hline Hand burns and escharotomy & Studies \#1 (retro), \#6 \\
\hline Cosmesis \& function (QOL) at 2-4 years & Study \#7 (Phase 3b) \\
\hline
\end{tabular}
\end{tabular}

\begin{tabular}{|c|c|c|c|c|}
\hline $\begin{array}{l}\text { Study } \\
\text { No. }\end{array}$ & Design & Patients & $\begin{array}{l}\text { Inclusion } \\
\text { criteria }\end{array}$ & Comparator(s) \\
\hline 1 & Open-label & 154 & $\begin{array}{l}\text { Age } 5 \mathrm{~m}-82 \mathrm{yrs} \\
\text { TBSA }<67 \%\end{array}$ & None \\
\hline 2 & $\begin{array}{l}\text { Blinded } \\
\text { RCT }\end{array}$ & 20 & $\begin{array}{l}\text { Age } 18-70 y r s \\
\text { TBSA }<15 \%\end{array}$ & $\begin{array}{l}1,2,4 \mathrm{gm} \\
\text { NXB }\end{array}$ \\
\hline 3 & $\begin{array}{l}\text { Open-label, } \\
\text { RCT }\end{array}$ & 140 & $\begin{array}{l}\text { Age } 18-70 y r s \\
\text { TBSA }<30 \%\end{array}$ & $\begin{array}{l}\text { NXB, vehicle, } \\
\text { SOC }\end{array}$ \\
\hline 4 & $\begin{array}{l}\text { Open-label, } \\
\text { RCT }\end{array}$ & 30 & $\begin{array}{l}\text { Age } 18-65 y r s \\
\text { TBSA }<10 \%\end{array}$ & $\begin{array}{l}\text { NXB, vehicle, } \\
\text { SOC }\end{array}$ \\
\hline 5 & Open-label & 33 & $\begin{array}{l}\text { Age } 4-70 y r s \\
\text { TBSA } 4-30 \%\end{array}$ & None \\
\hline 6 & $\begin{array}{l}\text { Open-label, } \\
\text { RCT phase } 3\end{array}$ & 156 & $\begin{array}{l}\text { Age } 4-55 y r s \\
\text { TBSA } 5-30 \%\end{array}$ & NXB, SOC \\
\hline 7 & $\begin{array}{l}\text { Assessor- } \\
\text { blinded RCT, } \\
\text { no drug }\end{array}$ & 89 & $\begin{array}{l}\text { Age } 4-55 y r s \\
\text { TBSA } 5-30 \%\end{array}$ & $\begin{array}{l}\text { NXB, SOC } \\
\text { Phase } 3 b \text {, } \\
\text { long term }\end{array}$ \\
\hline
\end{tabular}

Results: Data from over 550 treated burn patients demonstrates that debridement efficacy was $>90 \%$ in all studies, comparable to the soC debridement techniques and significantly greater than the control vehicle. The time to complete debridement demonstrated in the phase 3 RCT was significantly shorter for NXB vs. SOC ( 0.8 vs. 6.7 days from signing of ICF, $\mathrm{P}<0.0001)$. The incidence of surgical excision in NXB patients was lower than for SOC $(24.5 \%$ vs. $70.0 \%, P<0.001)$. The $\%$ wound area excised in NXB patients $(22.9 \%)$ was lower than in control vehicle patients $(73.2 \%, P<0.001)$ or SOC patients $(50.5 \%, P=0.006)$. Less autografting was used in NXB patients in all studies. Results of hand burns treated with NXB were even better, demonstrating even greater statistically significant benefits vs. SOC. Additionally, none of the 130 NXB treated hands throughout the entire clinical development program necessitated surgical escharotomy, vs. 4/41 SOC treated hands that did. The phase $3 \mathrm{~b}$ study demonstrates that long-term outcomes were favorable in NXB vs. the SOC patients (though NS) despite a slightly longer time to complete wound closure. The longer times to complete wound closure seen in NXB treated wounds are the result of opting for closure by spontaneous epithelialization over NXB salvaged viable dermis, which takes longer than for a skin graft closure. The favorable long term outcomes and lower incidences of scar modulation and reconstructive procedures needed in NXB treated patients demonstrate the importance of the salvaged dermis, as it is well known in burns that "Dermis is Quality of Life".

Conclusions: NXB has been proven to be effective, fast acting and undamaging to uninjured tissues with the potential for increased chances for spontaneous epithelialization. An overall reduced surgical burden with favorable long term outcomes can be the basis for a minimally invasive approach to burn care.
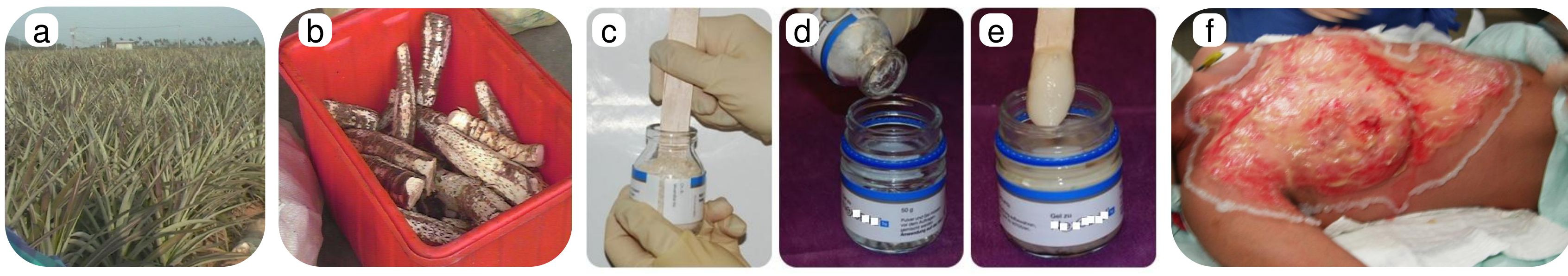

Figure 1: (a) pineapple field grown for NXB production. (b) pineapple stems. (c-d-e) NXB powder and gel mixed at patient's bedside. (f) NXB applied with a surrounding adhesive barrier. (g) occlusive dressing. (h) NXB and dissolved eschar scraped away from pinpoint bleeding viable wound bed after 4 hour treatment. (i) difference between surgical debridement - tangentially removing layer by layer of eschar and viable dermis indiscriminately, versus NXB debridement - selectively removing only eschar and salvaging viable dermis.
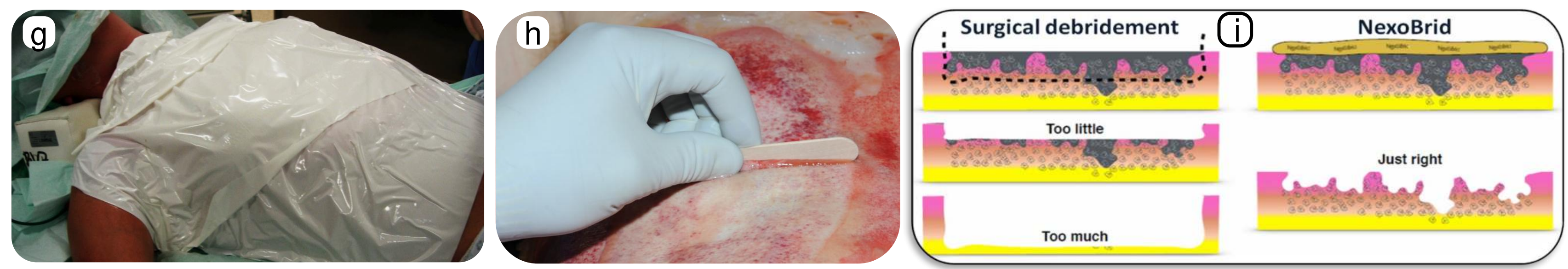